\title{
Muscle That Influence the Lumar Spine, Smallest Yet Most Powerful: Lumbar Multifidus
}

\author{
Arvind Kumar* \\ Shri USB College of Physiothreapy, MPT(Orthopedics), India
}

Received: 制 January 16, 2019; Published: 制 January 24, 2019

*Corresponding author: Arvind Kumar, MPT(Orthopaedics), MBA(Hospital Management),PhD Scholar, Principal, School of Physiotherapy, Swarnim Startup\&Innovation University, India

Abstract

It is well known that the lumbar multifidus muscle helps to stabilize and control of the lumbar spine. Some studies indicate a role of this muscle in spinal stiffness and control of intervertebral motion, particularly in the sagittal and frontal planes. Because the deep and superficial fibers of the multifidus are near the center of lumbar joint rotation, the superficial fibers are help to control spine orientation and the deep fibers helps to control intervertebral movement. If ligaments are insufficient than spinal movement is controlled by activity of multifidus.

\section{Introduction}

Some authors suggested that rather than increasing the strength or hypertrophy of the trunk muscles, the aim of therapeutic exercise in LBP should be to enhance the function of trunk muscles which are thought to be preferentially suited to stabilizing the lumbar spine [1-5]. In contrast to the general approach, this strategy aims to activate the lumbar multifidus independent of the other paraspinal muscles in the initial stages of rehabilitation and to then integrate appropriate multifidus activation into functional activities [5,6]. Specific exercises have been designed to activate the lumbar multifidus in an isometric, low load, tonic manner, while maintaining a neutral lumbar spine, to restore the proposed function of the lumbar multifidus and its contribution to spinal control [5-9]. The clinical literature has focused on the deep segmental fibers of the lumbar multifidus (DM) as the target of exercise interventions $[5,8,10]$. This specific type of exercise approach has been demonstrated to reduce recurrence following acute LBP [11] and to reduce pain and disability in patients with chronic LBP [6].

\section{Multifidus Muscle}

The multifidus muscle is one of the smallest and very important 'powerful" muscle that supports the spine. Many people think that small is insignificant, but its misconception only in this case. The multifidus muscle is a thin, long but very important muscle that extends nearly the entire length of spinal column. The only vertebra this muscle in not connected is C1. It originates from the back surface of the sacrum, the posterior superior iliac spine, the mammillary process of lumbar vertebrae, the transverse process of thoracic vertebrae, articular processes of the cervical vertebrae(C4-C7) and it inserts onto the spinous process of each vertebrae except $\mathrm{C} 1$.
The lumbar multifidus muscle provides lumbopelvic stability by controlling of intervertebral and sacrovertebral motion. The multifidus muscle is a series of muscles which are further divided into two groups i.e. the superficial fibers and deep fibers and both is having specific role. Recently, emphasis has shifted to the deep fibers of this muscle (DM) that DM stabilizes the lumbar spine whereas the superficial fibers of lumbar multifidus (SM) and the Erector Spinae (ES) extend and/or rotate the lumbar spine.

\section{Role of Multifidus Muscle}

The multifidus is an absolutely important muscle that stabilizes the spine. The vertebrae are under constant micro-motion feedback from the multifidus so that motion is allowed, but only a small amount in all of the right directions. Multifidi's Problem Causing Pain and Dysfunction. The back bones are out of control and there's too much sloppy motion. All of the extra movement can damage the disc space between the bones and the joints between them (facet joints), causing pinching of the spinal nerves. The multifidus muscles help to take pressure off the vertebral discs so that our body weight can be well distributed along the spine. Additionally, the superficial muscle group keeps our spine straight while the deep muscle group contributes significantly to the stability of our spine. These two groups of multifidus muscles are recruited during many actions in our daily living, which includes bending backward, sideways and even turning our body to the sides.

Studies have shown that the multifidus muscles get activated before any action is carried out so to protect our spine from injury. Take for example when you are about to carry an item or before moving your arm, the mutifidus muscles will start contracting prior 
to the actual movement of the body and the arm so as to prepare the spine for the movement and prevent it from getting hurt. In recent years, many studies have been carried out to identify the relationship between back pain and multifidus

\section{Discussion}

The superficial and deep fibers of the multifidus are controlled in different manner during movements of the upper limb that disturb the stability of the spine. Many studies shoes that the superficial fibers act to control orientation of spine and the deep fibers of the multifidus muscle control intersegmental stability. The segmental attachments of deep fibers provide flexibility which allow the neuromuscular system to control individual segments [13]. The deep multifidus muscle fibers has a greater proportion of slow twitch muscle fibers $[14,15]$. Majority of studies correlate atrophy of this muscle to pain, poor outcomes, muscle shrinking, changes in colour and functional problems. The latest research -The severity of multifidus atrophy on MRI is directly correlated with decreased ability to bend forward \& back pain Disc degeneration on MRI is associated with bone changes and multifidus atrophy indication a "Whole Organ "pathology. The fatty composition of the multifidus muscles in back pain was directly correlated to poor physical function. erch Phys. Since most of the studies conducted since 1993 show that multifidus atrophy is a real problem associated with back pain. There are many evidences of impairment of the multifidus in Back pain patients and pain has a adverse effect on the deep multifidus muscle which results as inhibition of this muscle, in other words pain itself can induce inhibition of the multifidus muscle. Different studies show LBP patients having wasting of multifidus

\section{Conclusion}

The superficial fibers of the multifidus and erector spinae are controlled in a direction-specific manner, consistent with control of spine orientation. However, the deep fibers of the multifidus may have a role in the control of intersegmental rotational and shear forces, probably through the exertion of compressive force between segments. When the vertical forces associated with arm movement are increased, such as during movement about $90^{\circ}$ flexion, there may be no requirement for the deep multifidus fibers to contribute to this end. Consequently, the deep multifidus is active in a similar fashion in relation to the other trunk muscles. The current study raises possible implications for the study and treatment of back pain. Previous research has demonstrated robust abnormalities of TrA motor control, which contributes to spine stability in patients with back pain $[16,17]$. Other studies have reported changes in multifidus morphology $[18,19]$ which may affect the deep portion of the muscle. The deep multifidus is controlled in a manner similar to TrA in asymptomatic subjects, and also may contribute to the control of intervertebral motion. Therefore, investigation of deep multifidus activity in clinical populations is warranted.

Currently, multifidus dysfunction is being increasingly implicated as a contributory factor in the development or recurrence of sub-acute and chronic mechanical back complaints. The current contribution wants to give insight into the anatomical structure of the multifidus and its response to LBP as crucial components for the development of accurate preventive and intervention strategies for LBP patients.

\section{References}

1. Crisco JJ, Panjabi MM (1991) The intersegment and multisegmental muscles of the lumbar spine: a biomechanical model comparing lateral stabilizing potential. Spine 16: 793-799.

2. Panjabi M, Abumi K, Duranceau J, Oxland T (1989) Spinal stability and intesegmental muscle forces: a biomechanical model. Spine 14: 194 -200 .

3. Wilke HJ, Wolf S, Claes LE, Arand M, Wiesend A (1995) Stability increase of the lumbar spine with different muscle groups: a biomechanicalin vitro study. Spine 20: 192-198.

4. Kaigle AM, Holm SH, Hansson TH (1995) Experimental instability in the lumbar spine. Spine 20(40: 421-430.

5. Richardson C, Jull G (1995) An historical perspective on the development of clinical techniques to evaluate and treat the active stabilizing system of the lumbar spine. The Australian Journal of Physiotherapy Monograph 1: $5-13$.

6. O'Sullivan PB PB, Phyty GD, Twomey LT, Allison GT (1997) Evaluation of specific stabilizing exercise in the treatment of chronic low back pain with radiologic diagnosis of spondylolysis or spondylolisthesis. Spine 22(24): 2959-2967.

7. Saal JA, Saal JS (1989) Nonoperative treatment of herniated lumbar intervertebral disc with radiculopathy. An outcome study. Spine 14(4): 431-437.

8. Richardson C, Jull G, Hodges P, Hides J (1999) Overview of the principles of clinical management of the deep muscle system for segmental stabilization. In: Therapeutic exercise for spinal segmental stabilization in low back pain. Churchill Livingstone pp. 93-102.

9. Richardson C, Jull G, Hides J (2000) A new clinical model of the muscle dysfunction linked to the disturbance of spinal stability: implications for treatment of low back pain. In: Twomey LT, Taylor JL, editors. Physical therapy for the low back ( $3^{\text {rd }}$ Edn). Churchill Livingstone, New York, USA, pp. 249-67.

10. Taylor J, O’Sullivan P (2000) Lumbar segmental instability: Pathology, diagnosis and conservative care. In: Twomey L, Taylor J, editors. Physical therapy of the low back ( $3^{\text {rd }}$ edn.), Churchill Livingstone, New York, USA, pp. 201-247.

11. Hides JA, Jull GA, Richardson CA (2001) Long-term effects of specific stabilizing exercises for first-episode low back pain. Spine 26(11): 243248.

12. O Sullivan PB, Phyty GD, Twomey LT, Allison GT (1997) Evaluation of specific stabilizing exercise in the treatment of chronic low back pain with radiologic diagnosis of spondylolysis or spondylolisthesis. Spine 22(24): 2959-2967.

13. Panjabi M, Abumi K, Duranceau J, Oxland T (1989) Spinal stability and intesegmental muscle forces: a biomechanical model. Spine 14: 194 -200 .

14. Jorgensen K, Nicholaisen T, Kato M (1993) Muscle fiber distribution, capillary density and enzymatic activities in the lumbar paravertebral muscles of young men: significance for isometric endurance. Spine 18(11): $1439-1450$.

15. Sirca A, Kostevc V (1985) The fibre type composition of thoracic and lumbar paravertebral muscles in man. J Anat 141: 131-137.

16. Hodges PW, Richardson CA (1998) Delayed postural contraction of transverses abdominis in low back pain associated with movement of the lower limb. J Spinal Disord 11: 46 -56. 
17. Hodges PW, Richardson CA (1996) Inefficient muscular stabilization of the lumbar spine associated with low back pain: a motor control evaluation of transversus abdominis. Spine 21(22): 2640-2650.

18. Hides JA, Richardson CA, Jull GA (1996) Multifidus muscle recovery is not automatic after resolution of acute, first-episode low back pain. Spine 21(23): 2763-2769.

\section{ISSN: 2574-1241}

DOI: 10.26717/BJSTR.2019.13.002417

Arvind Kumar. Biomed J Sci \& Tech Res

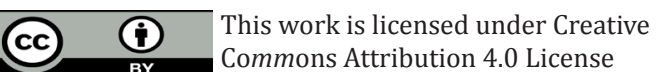

Submission Link: https://biomedres.us/submit-manuscript.php
19. Rantanen J, Hurme M, Falck B, Alaranta H, Nykvist F, et al. (1993) The lumbar multifidus muscle five years after surgery for a lumbar intervertebral disc herniation. Spine 18(5): 568-574.

$\begin{array}{ll}\text { BIOMEDICAL } & \text { Assets of Publishing with us } \\ \text { RESEARCHES } & \text { - Global archiving of articles } \\ \text { - Immediate, unrestricted online access }\end{array}$

